sizes should be reduced. Livestock should be valued for its quality rather than its abundance. If animal numbers in the Sahel were maintained at half the 1971 level, with modern management techniques the region's output of meat and milk could be double that level. Farming in the sedentary zones should also be improved, to halt its spread onto pasturelands. Farmers need knowledge and equipment to grow sufficient food using the best lands without loss of fertility; back-up for subsistence farmers has hitherto been neglected in favour of cash crops, $\mathbf{s}$ which have themselves exacerbated the lot of the rural poor.

In addition, couples must perceive the advantages of small families. Population growth, says the study, prohibits a return to the ecologically sustainable rotation systems, so new cropping systems, along with tree-planting programmes, are the only alternative. Also, to urge the resettling of nomads and the killing of goats is to oversimplify: a modernised version of the nomadic way of life may be necessary, with clan leaders, aided by specialised advice, regulating grazing and migration through large herding cooperatives.

A major goal of arid lands development, says the study, must be to prepare peoples and economies to live through the inevitable droughts without trauma. Protection against famine, it says, is not a simple technological problem. Its success depends on nothing less than "the broad shape of national development and the character of the prevailing socio-economic institutions".

Plainly the challenge is great. It is a challenge facing the UN Conference. If that fails, and past experience does not augur well, the people most affected will be left to face it alone. They have done so before. But their chances of successfully continuing to do so are not improving.
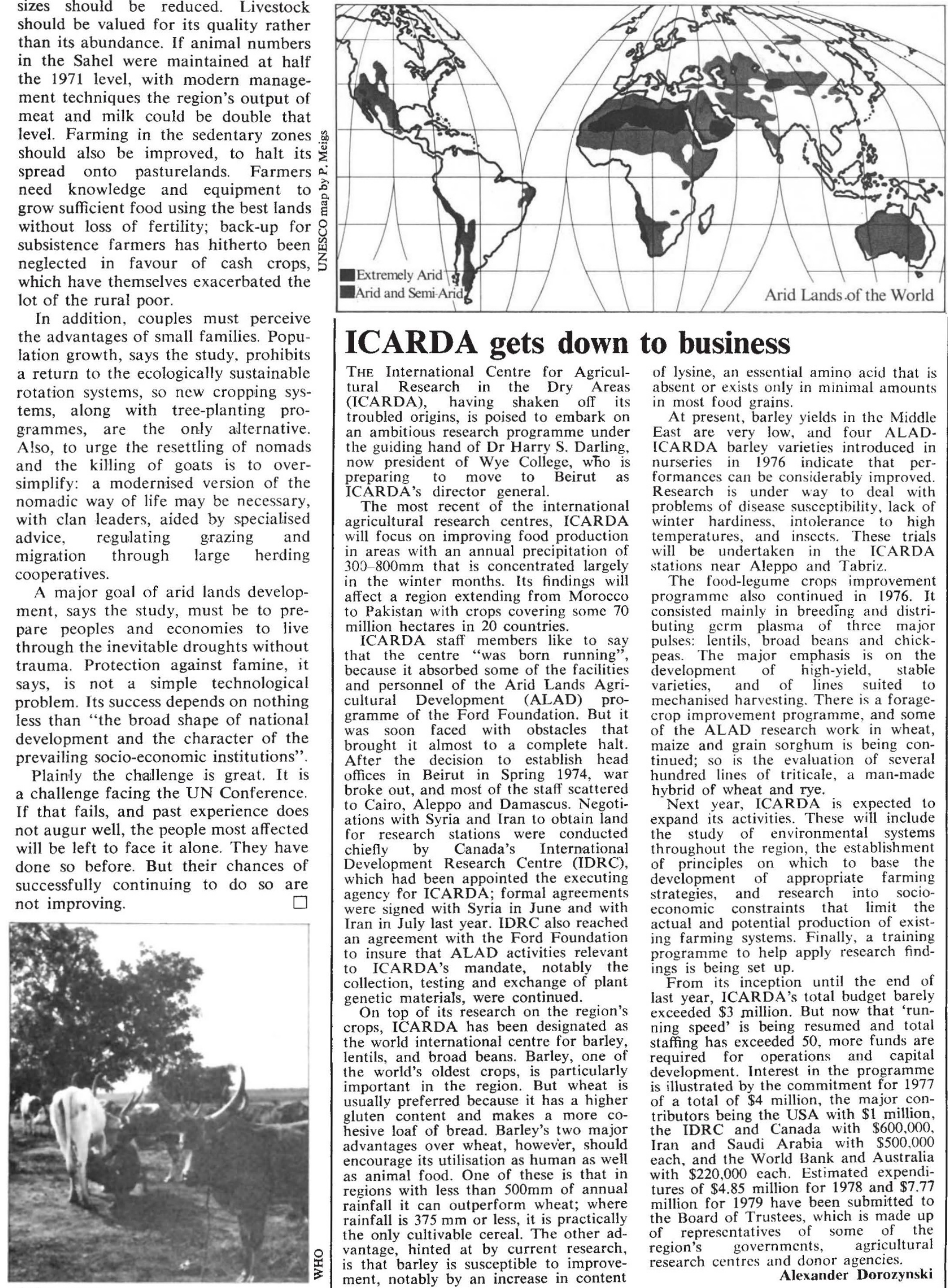

\title{
ICARDA gets down to business
}

THE International Centre for Agricultural Research in the Dry Areas (ICARDA), having shaken off its troubled origins, is poised to embark on an ambitious research programme under the guiding hand of Dr Harry S. Darling, now president of Wye College, who is preparing to move to Beirut as ICARDA's director general.

The most recent of the international agricultural research centres, ICARDA will focus on improving food production in areas with an annual precipitation of $300-800 \mathrm{~mm}$ that is concentrated largely in the winter months. Its findings will affect a region extending from Morocco to Pakistan with crops covering some 70 million hectares in 20 countries.

ICARDA staff members like to say that the centre "was born running", because it absorbed some of the facilities and personnel of the Arid Lands Agricultural Development (ALAD) programme of the Ford Foundation. But it was soon faced with obstacles that brought it almost to a complete halt. After the decision to establish head offices in Beirut in Spring 1974, war broke out, and most of the staff scattered to Cairo, Aleppo and Damascus. Negotiations with Syria and Iran to obtain land for research stations were conducted chiefly by Canada's International Development Research Centre (IDRC), which had been appointed the executing agency for ICARDA; formal agreements were signed with Syria in June and with Iran in July last year. IDRC also reached an agreement with the Ford Foundation to insure that ALAD activities relevant to ICARDA's mandate, notably the collection, testing and exchange of plant genetic materials, were continued.

On top of its research on the region's crops, ICARDA has been designated as the world international centre for barley, lentils, and broad beans. Barley, one of the world's oldest crops, is particularly important in the region. But wheat is usually preferred because it has a higher gluten content and makes a more cohesive loaf of bread. Barley's two major advantages over wheat, however, should encourage its utilisation as human as well as animal food. One of these is that in regions with less than $500 \mathrm{~mm}$ of annual rainfall it can outperform wheat; where rainfall is $375 \mathrm{~mm}$ or less, it is practically the only cultivable cereal. The other advantage, hinted at by current research, is that barley is susceptible to improvement, notably by an increase in content of lysine, an essential amino acid that is absent or exists only in minimal amounts in most food grains.

At present, barley yields in the Middle East are very low, and four ALAD. ICARDA barley varieties introduced in nurseries in 1976 indicate that performances can be considerably improved. Research is under way to deal with problems of disease susceptibility, lack of winter hardiness, intolerance to high temperatures, and insects. These trials will be undertaken in the ICARDA stations near Aleppo and Tabriz.

The food-legume crops improvement programme also continued in 1976. It consisted mainly in breeding and distributing germ plasma of three major pulses: lentils, broad beans and chickpeas. The major emphasis is on the development of high-yield, stable varieties, and of lines suited to mechanised harvesting. There is a foragecrop improvement programme, and some of the ALAD research work in wheat, maize and grain sorghum is being continued; so is the evaluation of several hundred lines of triticale, a man-made hybrid of wheat and rye.

Next year, ICARDA is expected to expand its activities. These will include the study of environmental systems throughout the region, the establishment of principles on which to base the development of appropriate farming strategies, and research into socioeconomic constraints that limit the actual and potential production of existing farming systems. Finally, a training programme to help apply research findings is being set up.

From its inception until the end of last year, ICARDA's total budget barely exceeded $\$ 3$ million. But now that 'running speed' is being resumed and total staffing has exceeded 50 , more funds are required for operations and capital development. Interest in the programme is illustrated by the commitment for 1977 of a total of $\$ 4$ million, the major contributors being the USA with $\$ 1$ million, the IDRC and Canada with $\$ 600,000$, Iran and Saudi Arabia with \$500,000 each, and the World Bank and Australia with $\$ 220,000$ each. Estimated expenditures of $\$ 4.85$ million for 1978 and $\$ 7.77$ million for 1979 have been submitted to the Board of Trustees, which is made up of representatives of some of the region's governments, agricultural research centres and donor agencies.

Alexander Dorozynski 